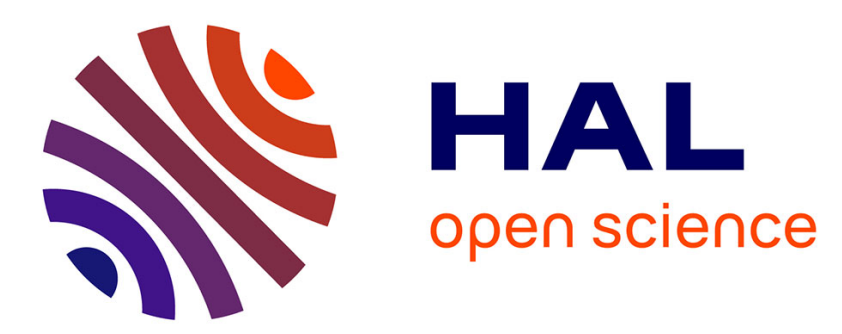

\title{
A RADIOACTIVE TRACER STUDY OF DIFFUSION PROCESSES IN LEAD AND SILVER BROMIDE
}

S. Rushbrook Williams, L. Barr

\section{To cite this version:}

S. Rushbrook Williams, L. Barr. A RADIOACTIVE TRACER STUDY OF DIFFUSION PROCESSES IN LEAD AND SILVER BROMIDE. Journal de Physique Colloques, 1973, 34 (C9), pp.C9173-C9-177. 10.1051/jphyscol:1973933 . jpa-00215408

\section{HAL Id: jpa-00215408 https://hal.science/jpa-00215408}

Submitted on 1 Jan 1973

HAL is a multi-disciplinary open access archive for the deposit and dissemination of scientific research documents, whether they are published or not. The documents may come from teaching and research institutions in France or abroad, or from public or private research centers.
L'archive ouverte pluridisciplinaire HAL, est destinée au dépôt et à la diffusion de documents scientifiques de niveau recherche, publiés ou non, émanant des établissements d'enseignement et de recherche français ou étrangers, des laboratoires publics ou privés. 


\title{
A RADIOACTIVE TRACER STUDY OF DIFFUSION PROCESSES IN LEAD AND SILVER BROMIDE
}

\author{
S. RUSHBROOK WILLIAMS and L. W. BARR
}

Physics Department, Paisley College of Technology, High Street, Paisley PA 12 BE, UK

\begin{abstract}
Résumé. - La diffusion de l'anion dans $\mathrm{PbBr}_{2}$ et $\mathrm{AgBr}$ a été étudiée à l'aide d'une méthode d'échange isotopique. La diffusion de $\mathrm{Pb}$ dans $\mathrm{PbBr}_{2}$ a été mesurée à l'aide de l'isotope $\mathrm{Pb}-210$ par la méthode de sectionnement chimique. L'effet de la pression de brome sur la diffusion de l'anion a été examiné dans les deux matériaux. Dans $\mathrm{PbBr}_{2}$, ces observations ont été complétées par des mesures de conductivité.

Dans $\mathrm{PbBr}_{2}$, les défauts prédominants sont des défauts de Schottky avec une énergie de formation de $1,65 \mathrm{eV}$ et une enthalpie de migration de l'anion de $0,3 \mathrm{I} \mathrm{eV}$.

L'interprétation des résultats dans $\mathrm{AgBr}$ est plus difficile car le diagramme $\operatorname{Ln} D=f(1 / T)$ n'est pas linéaire. L'influence de la pression sur le coefficient de diffusion suggère fortement qu'un mécanisme unique par lacune anionique n'est pas présent en toutes proportions.

La cinétique du dégagement de brome durant la photo-décomposition en lumière UV a été étudiée dans $\mathrm{AgBr}$ et $\mathrm{PbBr}_{2}$. Dans les deux cas la cinétique indique qu'un processus de diffusion limite la vitesse aux temps longs.
\end{abstract}

\begin{abstract}
Anion self-diffusion has been studied in $\mathrm{PbBr}_{2}$ and $\mathrm{AgBr}$ using an isotope exchange technique. In addition the diffusion of $\mathrm{Pb}$ in $\mathrm{PbBr}_{2}$ has been measured using $210 \mathrm{~Pb}$ as tracer and a chemical sectioning method. The effect of bromine gas pressure on anion diffusion has been examined for both materials. In the case of $\mathrm{PbBr}_{2}$ these observations have been supplemented by ionic conductivity measurements.

For $\mathrm{PbBr}_{2}$ the results indicate that the dominant defects are Schottky vacancies with a formation energy of $1.65 \mathrm{eV}$ and an anion mobility energy of $0.31 \mathrm{eV}$.

Interpretation of the results for $\mathrm{AgBr}$ is more difficult since the Arrhenius plot of the diffusion coefficient over the range $10^{-17}<D<10^{-9}\left(\mathrm{~cm}^{2} . \mathrm{s}^{-1}\right)$ shows no clear-cut linear region. The pressure variation of the diffusion coefficient, however, strongly suggests that a single anion vacancy mechanism does not operate to any extent.

The kinetics of bromine release during photo-decomposition in UV light has been studied for $\mathrm{AgBr}$ and $\mathrm{PbBr}_{2}$. In both cases the kinetics indicate that a diffusion controlled step is rate limiting at long times.
\end{abstract}

1. Introduction. - The study of defects in ionic crystals owes much to the application of the powerful tools of doping with aliovalent impurities to vary the defect concentration, and the combination of ionic conductivity and self-diffusion measurements. For recent reviews see Barr and Lidiard (1970) and Bénière (1972). In this paper the application of these tools to $\mathrm{PbBr}_{2}$ and $\mathrm{AgBr}$ is described. In addition the variation of anion diffusion with the pressure of the surrounding bromine gas is used to give further information about the defects.

$\mathrm{PbBr}_{2}$ has been extensively studied by Schoonman (1971) using ionic conductivity and he concludes that the dominant defects are Schottky vacancies with the anion vacancy the more mobile. However, since ionic conductivity cannot distinguish between anion and cation components nor deted clectrically neutral defects an investigation using difusion techniques is desirable. $\mathrm{PbBr}_{2}$, has the further interesting feature of an anisotropic lattice structure unlike the more extensively sudied alkali halides.
In the case of $\mathrm{AgBr}$ it is known (Friauf, 1957) that on the cation lattice Frenkel defects dominate. Measurements of bromine diffusion at high temperatures (Tannhauser, 1957) have shown that the anion contribution to the ionic conduction is negligible making self-diffusion measurements the only way to obtain information about the anion defects.

It is known (Verwey, 1967) that $\mathrm{PbBr}_{2}$ like $\mathrm{AgBr}$ decomposes under the action of UV light. The rate of halogen release clearly provides information about the photographic process but for experimental reasons such studies have been largely neglected in the past (Malinowski, 1970). Since a minor change in the isotope exchange technique permits such measurements to be made readily some preliminary experiments in this field are reported in this paper.

2. Experimental. - - The essentials of the isotope exchange technique have been described elsewhere (Barr and Dawson, 1965; Dawson, Barr and PittPladdy, 1966). The technique is based on isotopic 
exchange between an inactive bromine gas and a crystal uniformly labelled with radioactive ${ }^{82} \mathrm{Br}$ by neutron irradiation. Observation of the rate at which ${ }^{82} \mathrm{Br}$ appears in the gas phase enables the diffusion coefficient to be found. The method is sensitive and enables a large number of measurements to be made over a wide temperature range using only one crystal. Since the method is non-destructive ionic conductivity measurements on the same crystal are possible. Measurements of the variation of diffusion with bromine gas pressure are readily made by introducing additional inactive bromine into the system during an isothermal anneal.

Lead diffusion was measured by the conventional sectioning technique using as tracer ${ }^{210} \mathrm{~Pb}$ deposited on the crystal from a $\mathrm{PbBr}_{2}$-hydrobromic acid solution. Because of the smallness of the lead diffusion sectioning was done by etching in dilute hydrobromic acid. The etchant was counted in a well-type scintillation counter using the $\gamma$ 's at 0.033 and $0.047 \mathrm{MeV}$.

The crystal structure of $\mathrm{PbBr}_{2}$ is the $\mathrm{PbCl}_{2}$ structure (Schoonman, 1971). The anion lattice is a slightly distorted hexagonal close packed structure. Conductivity measurements parallel to and at right angles to the $C$-axis showed no difference in activation energy and magnitude within the experimental error. For this reason the bromine diffusion is considered to be isotropic. This simplifies analysis of the exchange data. However, the largest area of face in the exchange measurements was normal to the $C$-axis.

The cation lattice is more complex and has the interesting feature that each lead ion has two nearest neighbours which form linear chains along the $C$-axis. Diffusion along such linear chains is, of course, highly correlated (Barr and Le Claire, 1964). Lead diffusion, and ionic conductivity, were always measured parallel to the $C$-axis.

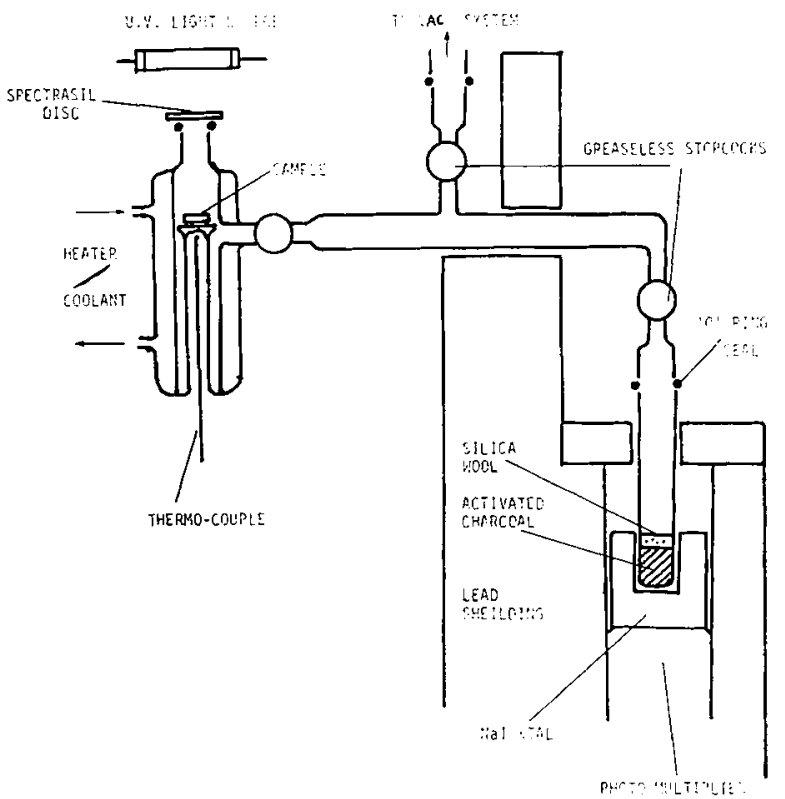

FIG. 1. - Apparatus for studying bromine release during UV irradiation.
Initially measurements of the bromine release during photodecomposition were done in the exchange apparatus simply by omitting the bromine exchange gas, thus leaving a vacuum to act as the bromine acceptor, and by arranging that the sample could be irradiated with UV light through a spectrosil window. Later the apparatus shown in figure 1 was used. Here the activated charcoal acted as the bromine trap after the apparatus had been evacuated to $2 \times 10^{-5}$ torr. The activity of the ${ }^{82} \mathrm{Br}$ released was then measured using a well-type scintillation counter.

3. Results and discussion. - 3.1 LEAD BROMIDE. In figure 2 Arrhenius plots are shown for bromine

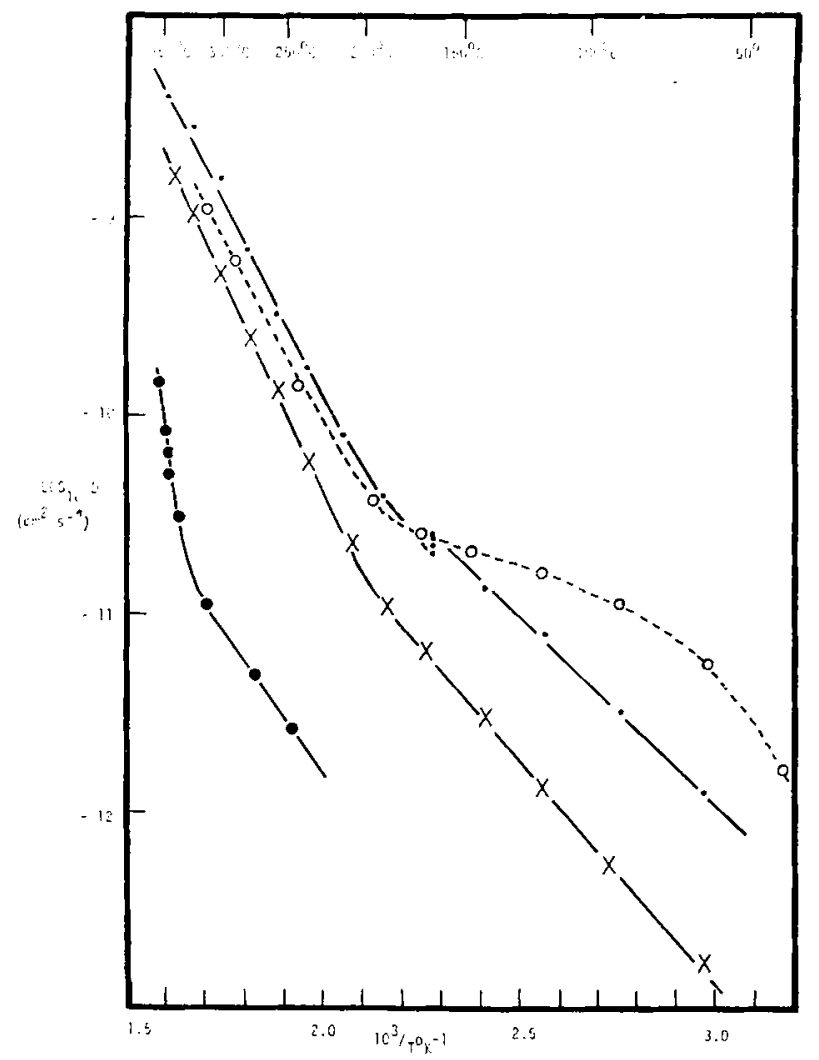

Fig. 2. - Bromine and lead diffusion in crystals of $\mathrm{PbBr}_{2}$, $\times \mathrm{Br}$ diffusion, pure crystal.

- Br diffusion, Tl doped.

O Br diffusion, neutron irradiated unannealed crystal.

- $\mathrm{Pb}$ diffusion.

and lead diffusion in $\mathrm{PbBr}_{2}$. The result for the irradiated crystal illustrates that the isotope exchange technique can be readily applied to studies of radiation damage. This crystal received the normal neutron irradiation $\left(6 \times 10^{15}\right.$ neutrons. $\left.\mathrm{cm}^{-2}\right)$ to activate the ${ }^{81} \mathrm{Br}$ to ${ }^{82} \mathrm{Br}$ but was not annealed before diffusion was measured. The standard anneal is for $50 \mathrm{~h}$ at $275^{\circ} \mathrm{C}$

At $160{ }^{\circ} \mathrm{C}$ in the thallium doped crystal can be seen the results of an isothermal increase in bromine pressure.

The experimental results for the pure and $\mathrm{Tl}$ 
doped crystals are interpreted as intrinsic and extrinsic regions with the extrinsic region of the $\mathrm{Tl}$ doped crystal much higher than in the pure crystal and the intrinsic region not being completely attained.

When corrections are applied to reduce the results to zero bromine pressure the clearly extrinsic regions of both the pure and doped crystals have the same activation energy of $0.31 \pm 0.02 \mathrm{eV}$. In the intrinsic region of the pure crystal the activation energy is $0.86 \pm 0.02 \mathrm{eV}$. These figures are compared in the table with the conductivity results of other workers.

\section{TABLE I}

\section{Activation energy of anion}

Source

\section{Present Work \\ Verwey (1967)}

Smakala (1965)

Schoonman (1967)

Hoshino (1973) motion (eV)

Schottky

formation

energy $(\mathrm{eV})$

$0.31 \pm 0.05$

$1.65 \pm 0.05$

0.29

0.28

0.25

0.23

where $\mathrm{V}_{\mathrm{Br}}$ is the bromine vacancy concentration, and the change in the anion vacancy concentration is small compared with the vacancy concentration at zero pressure, then

$$
\frac{\Delta D}{D} \propto-P^{1 / 2}
$$

and a plot of $\triangle D / D$ should decrease linearly with $P^{1 / 2}$ as is found in figure 3 . This confirms the interpretation of the diffusion in terms of a vacancy defect. Clearly the variation of lead diffusion with bromine pressure would provide a useful confirmation of this analysis.

In figure 4 conductivity, anion and cation diffusion results for the same (pure) crystal of $\mathrm{PbBr}_{2}$ are collected together. For convenience the conductivity curve, converted using the Nernst-Einstein equation, is divided into the four regions shown.

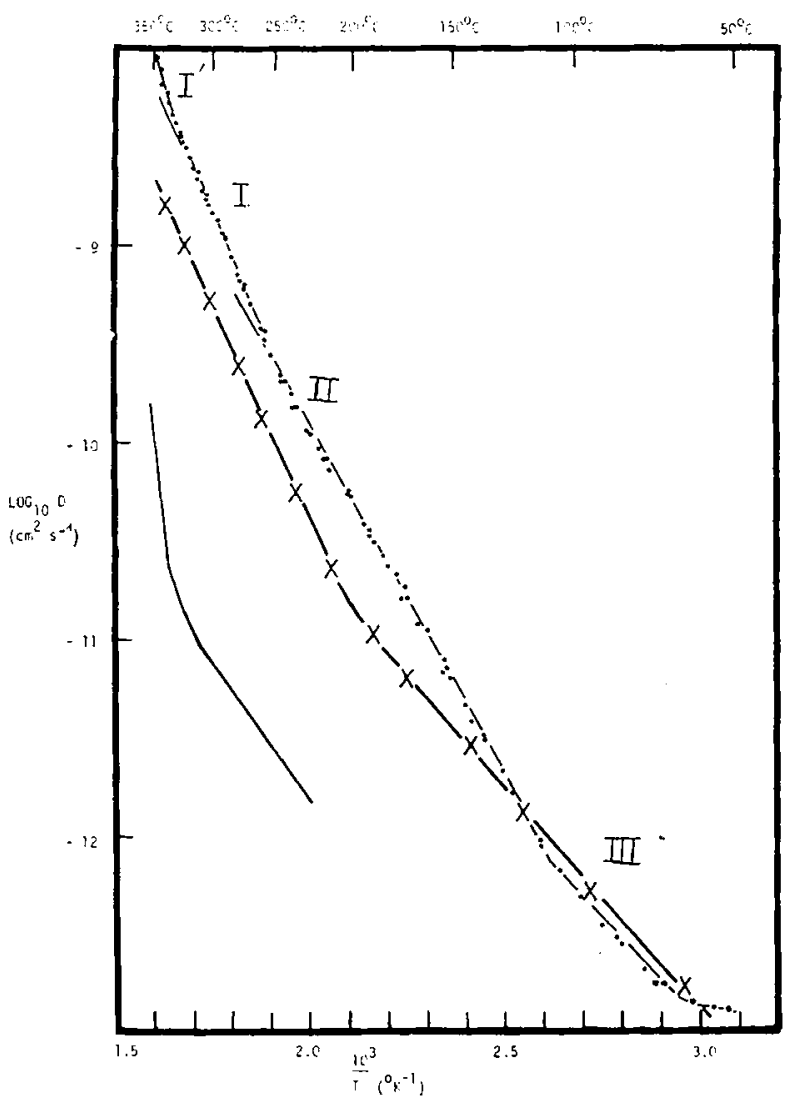

FIG. 4. - Comparison of $\mathrm{Br}$ and $\mathrm{Pb}$ diffusion and ionic conductivity in $\mathrm{PbBr}_{2}$.

$$
\begin{aligned}
& \times \mathrm{Br} \text { diffusion. } \\
& \text { Ionic conductivity. } \\
& \text { Solid line } \mathrm{Pb} \text { diffusion. }
\end{aligned}
$$

The $\mathrm{Pb}$ diffusion line is the same as in figure 2 and clearly makes little contribution to the conductivity save at the very highest temperatures within $10 \mathrm{~K}$ of the melting point. This is in line with transport number measurements (Tubant, 1920) and 
confirms the analysis of conductivity data in terms of anionic defects.

Schoonman interpreted region II (activation energy $0.73 \mathrm{eV}$ ) as the intrinsic region but since the "Knee » in the diffusion curve lies above $200{ }^{\circ} \mathrm{C}$ we believe that region $I$ (activation energy $=0.92 \pm 0.02 \mathrm{eV}$ ) is the intrinsic conduction region. Using this interpretation and neglecting any $\mathrm{Pb}$ contribution to conductivity we find a correlation factor for bromine diffusion of $0.75 \pm 0.1$ which is what would be expected on the basis of a vacancy mechanism. How region II should be interpreted is then not clear but the above conclusion is reinforced by the measurements of Hoshino and his co-workers (1973) who do not observe region II in their work.

Region III is clearly the extrinsic region and since the bromine diffusion lies slightly above the conduction line some, probably a small fraction, of the anion diffusion must be by an associated defect. That such association of anion vacancies occurs is confirmed by a distinct concavity in the low temperature extrinsic region in diffusion measurements in heavily doped crystals. A trace of such concavity can be seen in the $\mathrm{Tl}$ doped crystal of figure 2 . If such association is appreciable the activation energy of motion given in table I might be slightly high.

The very sharp rise in conductivity close to the melting point, stage $\mathrm{I}^{\prime}$, seems to be associated with the sharp rise in $\mathrm{Pb}$ diffusion at the same temperature. If this is the case the $\mathrm{Pb}$ diffusion must be very highly correlated which is plausible in view of the linear chains parallel to $C$-axis in the cation structure. It should, however, be remarked here that this high temperature stage is not always observed in the conductivity. Clearly high temperature conductivity and $\mathrm{Pb}$ diffusion measurements are necessary to understand the physical processes occurring.

3.2 AgBr. - The Arrhenius plot for the case of $\mathrm{Br}$ diffusion in $\mathrm{AgBr}$ is shown in figure 5. Again the suitability of the exchange technique for studies of radiation damage can be seen.

In figure 6 the variation of diffusion with bromine pressure is shown. It will be seen that the diffusion varies linearly with $P$. Since a vacancy mechanism predicts a decrease with $P^{1 / 2}$ this result strongly suggests that single anion vacancies do not contribute significantly to anion diffusion in $\mathrm{AgBr}$. The smoothly curved Arrhenius plot similarly suggests that more than one mechanism is active.

3. 3 Photodecomposition. - The kinetics of photodecomposition of both crystals, although structurally different, have striking similarities. In figure 7 is shown as an example the kinetics of bromine release from $\mathrm{PbBr}_{2}$. Apart from changes of scale it is identical with a similar plot for $\mathrm{AgBr}$.

Noteworthy are :

1) the initial region where the bromine release is linear with time,

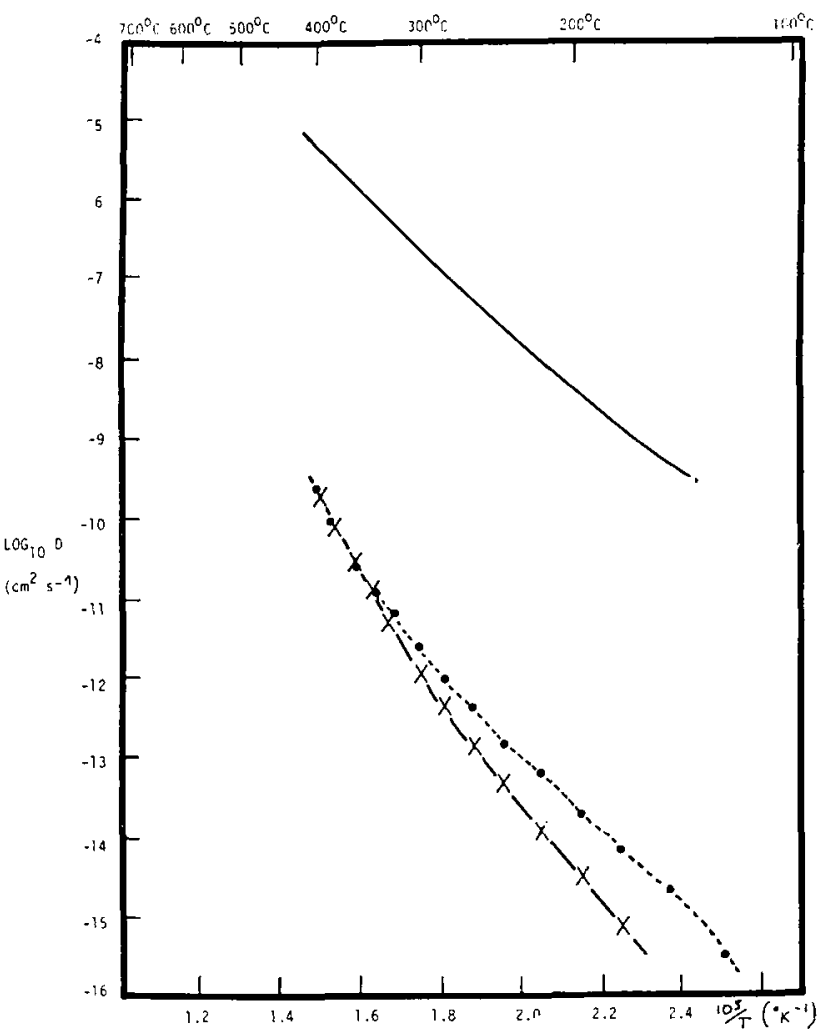

FIG. 5. - Comparison of $\mathrm{Br}$ and $\mathrm{Ag}$ diffusion in $\mathrm{AgBr}$.

$\times \mathrm{Br}$ diffusion, pure crystal.

- Br diffusion, neutron irradiated unannealed crystal. Solid line Ag diffusion.

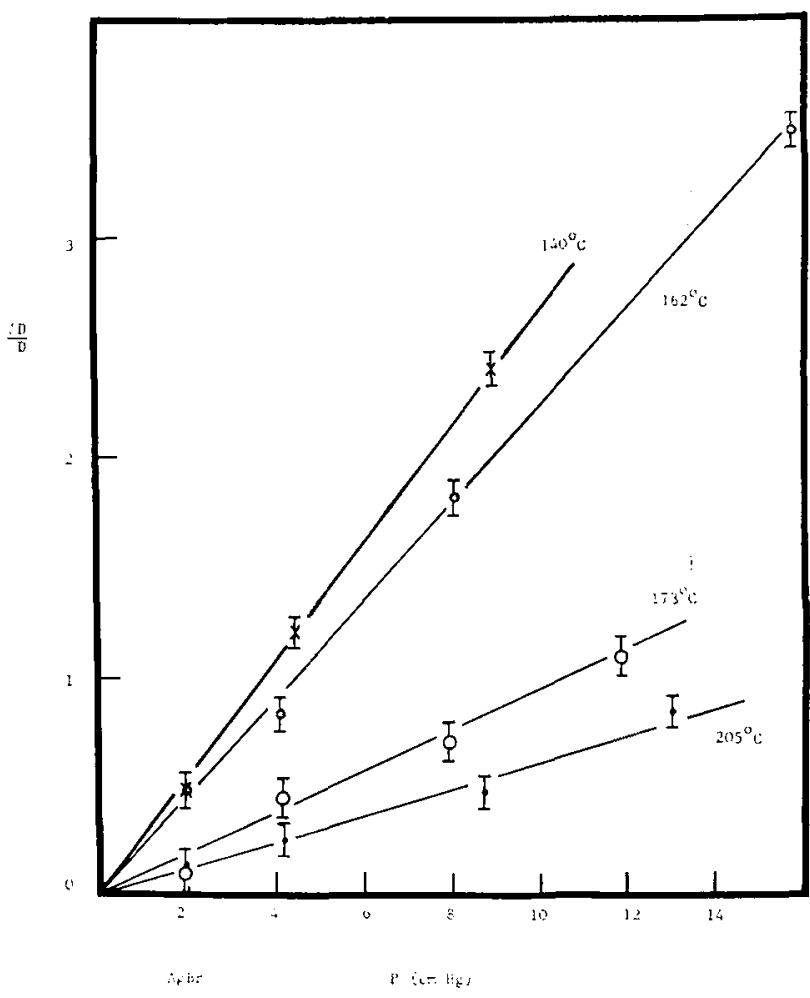

FIG. 6. - Variation of $\mathrm{Br}$ diffusion in $\mathrm{AgBr}$ with bromine pressure. 


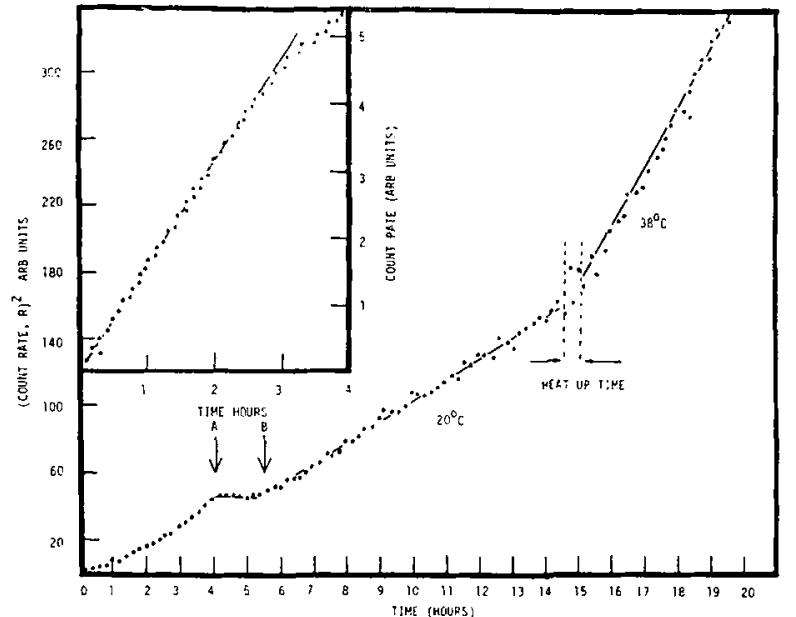

Fig. 7. $-\mathrm{Br}$ release from $\mathrm{PbBr}_{2}$ as a function of time under UV illumination. $A$ lamp off, $B$ lamp on.

2) the gradual transition to a region where the amount released is accurately linear with the square root of time,

3) the immediate cessation of bromine release when the UV illumination is stopped and the equally immediate restart on illuminating,

4) the change in release rate on changing the temperature.

In figure 8 a plot is given of the rate of release as a function of temperature. In this the two crystals differ. While $\mathrm{PbBr}_{2}$ shows a steady increase in release rate as temperature increases, $\mathrm{AgBr}$ passes through a broad maximum around room temperature. The results for $\mathrm{PbBr}_{2}$ can be described as an activated process with an activation energy of $0.16 \pm 0.02 \mathrm{eV}$ which is similar to the value found by Verwey (1970) by other means.

Because of the closeness with which the ${ }^{82} \mathrm{Br}$ release under UV illumination follows a square root rela-

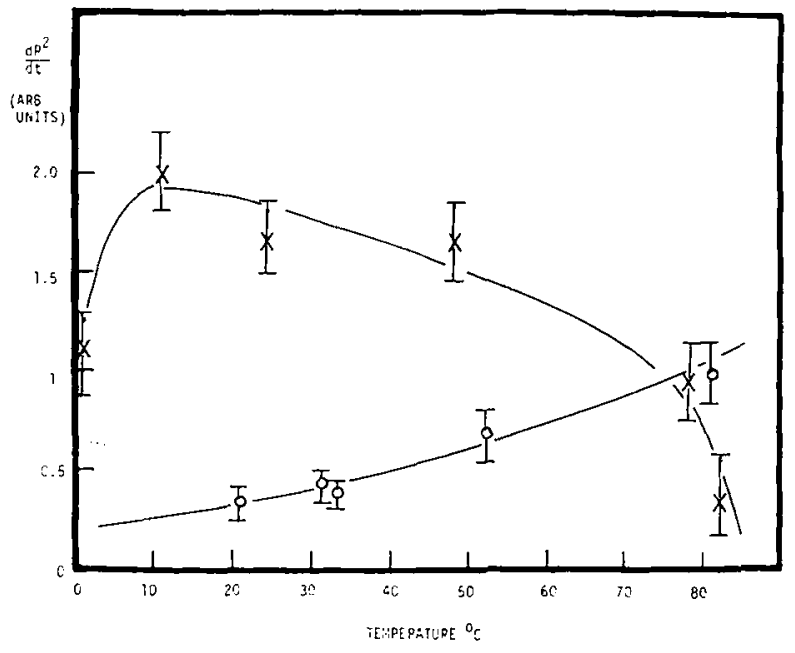

Fig. 8. - Temperature variation of $\mathrm{Br}$ release rate as a function of temperature in $\mathrm{PbBr}_{2}$ and $\mathrm{AgBr}$.

$$
\begin{aligned}
& \times \mathrm{Br} \text { release rate from } \mathrm{AgBr} \text {. } \\
& \circ \mathrm{Br} \text { release rate from } \mathrm{PbBr}_{2} \text {. }
\end{aligned}
$$

tionship it is very tempting to ascribe this to a diffusion controlled process. However, until further results are available this conclusion must be tentative.

4. Conclusions. - The high sensitivity of the isotope exchange technique and its application to the measurement of diffusion as a function of halogen pressure has been shown to be of great use in studies of diffusion mechanisms. Coupled with the more conventional techniques of diffusion measurement and ionic conductivity on pure and doped crystals it has enabled some progress to be made in understanding the defect structure of $\mathrm{PbBr}_{2}$ and $\mathrm{AgBr}$. In addition its application in a slightly modified form to photodecomposition has yielded unexpected results in this field.

References

Barr, L. W. and Dawson, D. K., Proc. Brit. Ceram. Soc. 5 (1965) 77.

Barr, L. W. and Lidiard, A. B., Physical Chemistry, Vol. X, W. Jost. ed. (Academic Press, New York, London) 1970.

Barr, L. W. and le Claire, A. D., Proc. Brit. Ceram. Soc. 1 (1964) 109.

BÉNIĖRe, F., Physics of Electrolytes, Vol. 1, J. Hladik. ed. (Academic Press, New York, London) 1972.

Dawson, D. K., Barr, L. W. and Pitt-Pladdy, R. A., Brit. J. Appl. Phys. 17 (1966) 657.
Friauf, R. J., Phy's. Rev. 105 (1957) 843.

Hoshino, H. and Yokose, S. and Shimoj, M., J. Solid State Chem. 7 (1973) 1.

Malinowski, J., Photog. Sci. \& Eng. 19 (1970) 2.

Schoonman, J., Thesis, University of Utrecht, 1971.

Schoonman, J., J. Solid State Chem. 2 (1970) 31.

Tannhauser, D. S., J. Phys. \& Chem. Solids 5 (1958) 224.

Tubant, C. and Eggert, S., Z. Anorg. Chem. 110 (1920) 196.

VERWEY, J. F., Thesis, University of Utrecht, 1967.

Verwey, J. F., J. Phys. \& Chem. Solids 31 (1970) 163.

Verwey, J. F. and Schoonman, J., Physica 35 (1967) 386. 